\title{
Secondary School Biology Students' Attitudes towards Modern Biotechnology Characterised using Structural Equation Modeling
}

\author{
Ola Nordqvist ${ }^{1^{*}}$, Stefan Johansson ${ }^{2}$ \\ ${ }^{1}$ Department of Biological and Environmental Sciences, University of Gothenburg, SWEDEN \\ ${ }^{2}$ Department of Education and Special Education, University of Gothenburg, SWEDEN
}

Received 16 October 2019 - Revised 27 November 2019 • Accepted 3 December 2019

\begin{abstract}
In biotechnology education research (BTER), the multifaceted construct of attitude has seldom been problematised in depth despite that the majority of studies in BTER during the last two decades have focused on students' attitudes towards modern biotechnology. Most studies on attitudes in science education use a single-factor model in characterising students' attitudes, while some use a three-factor model. By means of structural equation modeling the current study tested and evaluated single, three-factor, and bifactor models of student attitudes towards modern biotechnology. To further shed light on the stability of this model measurement invariance testing was carried out for groups; school-type, gender, grade, parental education and educational programme. The results showed that a three-factor model and a bifactor model showed satisfying fit to the student attitude data. The bifactor model were relatively invariant for all groups except for gender, where boys had a more positive attitude. The affective and behavioural aspects of attitudes were highly correlated why the bifactor model with its general factor and specific cognitive factor may provide a more sound explanation of students' attitudes towards biotechnology. The results indicate the importance of including affective and behavioural dimensions of attitude in biotechnology teaching. Further implications for practice are discussed.
\end{abstract}

Keywords: attitudes, bifactor model, biotechnology education, secondary schools students, structural equation modeling

\section{INTRODUCTION}

Modern biotechnology has been, from the turn of the century, an integrated part of upper secondary science curricula in many countries around the world such as England, New Zealand, Canada, Turkey, and the United States (France, 2007; Severcan, Ozan, \& Haris, 2000; Zeller, 1994). Educational literature on modern biotechnology discusses not only theoretical and technological aspects, but also possibilities and potential risks. Therefore, students' attitudes towards modern biotechnology have become a factor in student learning to a greater extent in the study of biotechnology as compared with the majority of other science areas. Prospects and risks with products and applications in modern biotechnology do affect students' attitudes. Hence, science education researchers have, over the last decades, investigated aspects of students' attitudes towards biotechnology with various research designs and methods (Nordqvist \& Aronsson, 2019).

The observed increased research interest on students attitudes in science in the last decade is in part prompted by the evident negative trend in interest in school science over time (Aikenhead, 2004; Gilbert, 2006; Osborne, Simon, \& Collins, 2003) and as students progresses through the school system (Christidou, 2011; Potvin \& Hasni, 2014a), particularly in Western countries. Another reason for the increased research interest in students attitudes is the promise of emerging research methods (Osborne et al., 2003). In order to gain deeper understanding of students' cognitive learning, it is important to examine attitudinal constructs in science education as they affect the cognitive domain. Koballa \& Glynn (2007, p. 76) further adds rationale for research on students attitudes in science when they state that "attitudinal [...] constructs [act] as moderators of a learner's conceptual change and suggest that

(C) 2020 by the authors; licensee Modestum Ltd., UK. This article is an open access article distributed under the terms and conditions of the Creative Commons Attribution License (http://creativecommons.org/licenses/by/4.0/). \ola.nordqvist@bioenv.gu.se (*Correspondence) \stefan.johansson@gu.se 


\section{Contribution of this paper to the literature}

- The methodological approach (structural equation modelling) applied in this study has rarely been used in the biotechnology education research context.

- The study evaluate three theoretical models on attitudes towards biotechnology education.

- Results suggested that students' attitudes towards modern biotechnology can be characterized as comprising one general factor and one specific factor.

they may influence science learning in the short term and over longer periods of time". Attitude is the critically most important construct in the affective domain in science education. While the importance of affective dimensions in science learning has been emphasized by researchers in recent years, attention to cognitive dimensions of learning still is more common in research (Koballa Jr \& Glynn, 2007).

This study will extend the body of research on students' attitudes towards biotechnology specifically by means of an analytical method rarely used in this research context - structural equation modeling (SEM). The intent with this approach is to shed light on different ways on how to operationalise students' attitudes towards modern biotechnology as well as suggesting alterative models to increase the precision of measurement.

\section{Attitude Models}

Researchers have over the last century problematised, analysed, and refined definitions of the sociopsychological construct of attitudes, and although several models to define attitudes have been attempted, two general models are dominant in recent research - unitary and tripartite attitude models.

Unitary (single-factor) models, where an attitude is seen as a single positive or negative evaluation of feelings towards a specific or psychological object, are identified in the majority of studies on attitudes in various sociological, psychological, and educational research contexts (Ajzen \& Fishbein, 2000; Eagly \& Chaiken, 1993; Weinburgh \& Englehard Jr, 1994; Zacharia \& Barton, 2004). Fishbein and Ajzen (1975, p.5) concluded, regarding attitude as a unitary model, that "most investigators would probably agree that attitude can be described as a learned predisposition to respond in a consistently favourable or unfavourable manner toward an attitude object", that is, attitude is defined as a feeling or an affective notion towards an object (Figure 1).

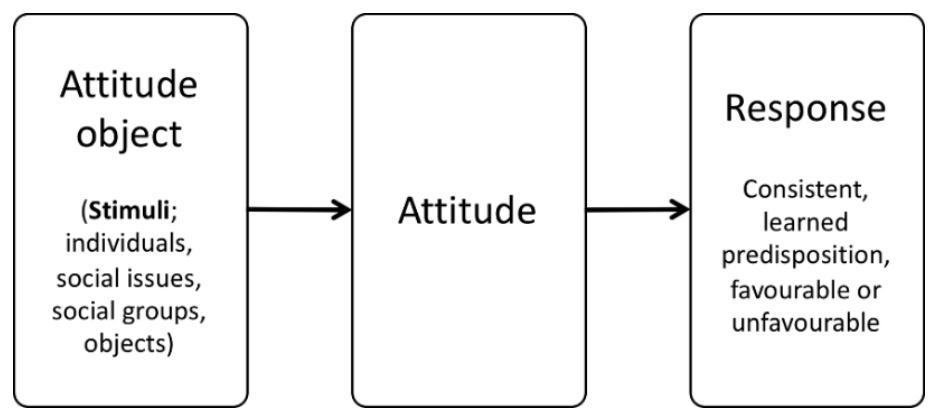

Figure 1. Conceptualising a general unitary model of attitudes (adapted from Fishbein \& Ajzen, 1975 and Rosenberg \& Hovland, 1960)

Tripartite (three-factor) models further deconstruct the construct of attitude into three separate components: an affective, a behavioural, and a cognitive component, which build the tripartite attitude construct (Figure 2) (Breckler, 1984; Eagly \& Chaiken, 1993; Rosenberg \& Hovland, 1960). In studies and discussions on the general socio-psychological construct of attitudes, the tripartite model is more frequently cited and used than unitary models (Eagly \& Chaiken, 1998; Fazio \& Olson, 2007). In studies where the attitude construct has been elaborated in educational science, the tripartite model is also predominantly used (Potvin \& Hasni, 2014b). This study will refer to the three-component model as the tripartite model. 


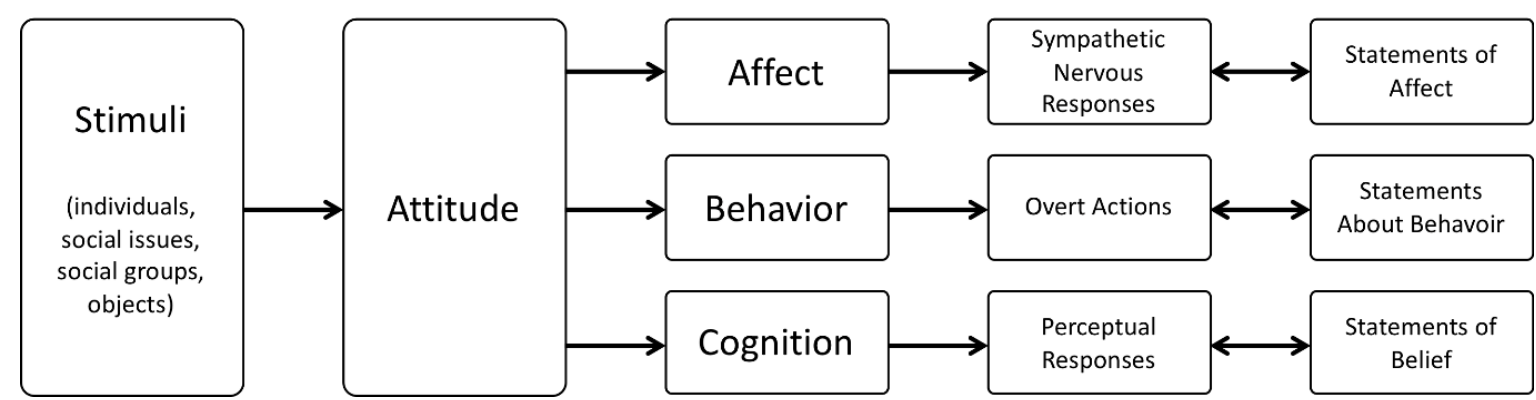

Figure 2. Conceptualising the tripartite model of attitudes (adapted from Rosenberg \& Hovland, 1960 and Breckler, 1984)

\section{Attitude Models in Science Education Research}

In the context of science education research or more specifically biotechnology education research (BTER), the construct of attitude has not been problematised with the same rigour as in other research contexts, such as the behavioural or psychological sciences. Previous research in science education has highlighted that the construct has often simply been referred to as attitude (Potvin \& Hasni, 2014b), and the same trend is found in BTER (Nordqvist \& Aronsson, 2019). In the science education context, where the construct has been problematised, the models used are the unitary model and the tripartite model. For example, instruments used to asses students science attitudes has historically not distinguished between the affective, behavioural or cognitive components of the tripartite model, but rather on the affective or evaluative components (Koballa Jr \& Glynn, 2007)

There are several examples of studies on attitudes in BTER using specific unitary models or undefined basic attitude models (Casanoves, Gonzalez, Salvado, Haro, \& Novo, 2015; S. Y. Chen, Chu, Lin, \& Chiang, 2016; Dawson \& Schibeci, 2003; Kidman, 2009; Mowen, Roberts, Wingenbach, \& Harlin, 2007; Prokop, Lešková, Kubiatko, \& Diran, 2007). This approach also holds true for studies in other related research areas such as attitudes towards modern biotechnology among the general public or among consumers (Costa-Font \& Mossialos, 2006; Gaskell et al., 2004; Magnusson \& Hursti, 2002). Studies where the attitude model has not been defined or explained mostly resemble studies using the unitary model, sometimes in combination with a behavioural component.

In BTER there are fewer examples of using the tripartite model, with all three components investigated and analysed separately, but there are some (Fonseca, Costa, Lencastre, \& Tavares, 2012a; Haidar, Chouman, \& Tayeh, 2014; Klop, 2008). Klop (2008) graphically outlined a conceptual framework of attitudes towards modern biotechnology that depicts the tripartite construct (Figure 3).

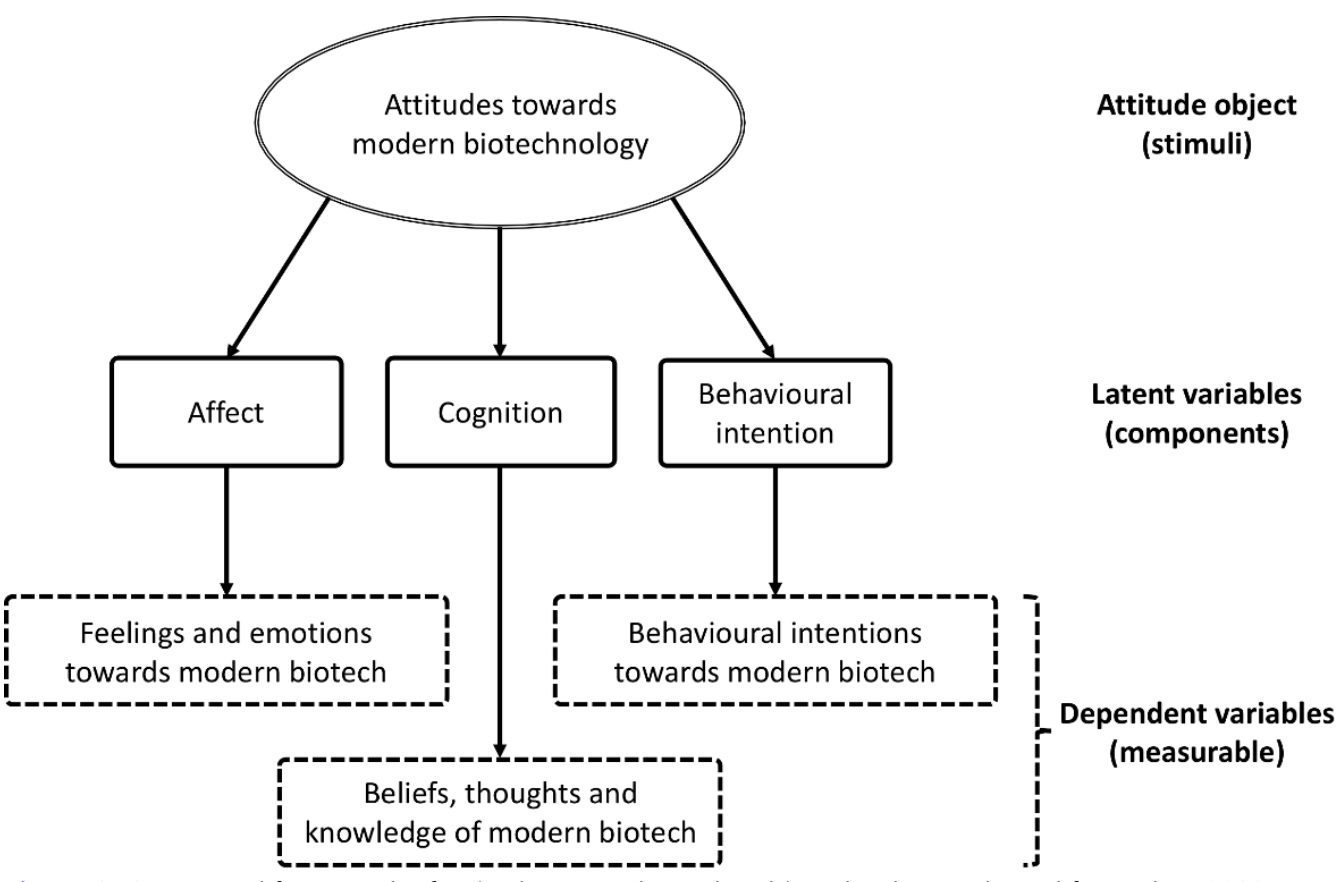

Figure 3. Conceptual framework of attitudes towards modern biotechnology (adapted from Klop, 2008) 
It could be argued that neither of the two general models (unitary or tripartite) are superior to the other in the context of attitudes towards modern biotechnology. Science topics in general and biotechnology in specific can be viewed as too complex to be described and explained by one component, and therefore there is a need to use attitude constructs beyond unitary models (Pardo \& Calvo, 2002). This study argue that standpoint. On the other hand, it has been argued that due to the complexity of diverse and complex subjects, such as modern biotechnology, attitudes are less based on logical reasoning and more based on gut feeling (Ajzen, 2001; Ajzen \& Fishbein, 2000; Pardo \& Calvo, 2002). That the attitude is a merely a single gut feeling would then favour using a unitary attitude model over other models. This holds especially true if the content knowledge among respondents is not up to par in the given context.

In educational settings like the one in this study where the students are in a similar educational context, more studies using the tripartite model would give a fuller picture of the attitude construct. By analysing the three components separately, rather than using unitary or undefined models, a more nuanced discussion of the results is possible, and conclusions about students' attitudes can be more informative. Or in the words of Koballa (1988, p.166), "Science educators, however, must define the term [attitude] carefully for themselves if it is to be used to better understand and predict the science-related behaviors of students and teachers" (Koballa Jr, 1988).

In BTER studies over the last two decades, similarities in topics investigated, methods used, and analyses made have been evident. Moreover, studies on attitudes towards modern biotechnology among students outnumber studies on all other concepts, with studies on biotechnology content knowledge as the runner-up (Nordqvist \& Aronsson, 2019). Most of these studies have been descriptive in nature, with analysis of frequencies, correlations, rankings, and so on, while only a few have investigated more complex patterns. This is in line with the trend found within the more general context of science education research (Potvin \& Hasni, 2014b).

\section{Previous Research on Students' Attitudes towards Biotechnology}

The majority of studies in BTER on students' attitudes have indicated that there is a positive correlation between content knowledge and positive attitudes towards biotechnological applications and products (S. Y. Chen et al., 2016; Dawson \& Schibeci, 2003; Fonseca, Costa, Lencastre, \& Tavares, 2012b; Klop, Severiens, Knippels, van Mil, \& Ten Dam, 2010; Prokop et al., 2007). On the other hand, there are also a few studies that do not find the same pattern and instead indicate a non-significant correlation between content knowledge and attitudes towards biotechnology (Sorgo \& Ambrozic-Dolinsek, 2009; Usak, Erdogan, Prokop, \& Ozel, 2009). Hence, findings about the relationship between content knowledge and attitudes towards modern biotechnology among students seem to be somewhat inconclusive. Even though this discrepancy, prevailing research findings do in general support a positive correlation between content knowledge and attitudes towards biotechnology as discussed above.

Other studies show that younger students hold a more negative attitude towards biotechnology than older students do (S. Y. Chen \& Raffan, 1999; Dawson, 2006; Usak et al., 2009). It is reasonable to assume that this is due to a lower level of topic-specific content knowledge or general science knowledge. The conclusions of studies using the unitary attitude model (Crne-Hladnik, Peklaj, Kosmelj, Hladnik, \& Javornik, 2009; Finke \& Kim, 2004; Prokop et al., 2007) also seem to provide evidence that boys generally have more positive attitudes towards modern biotechnology than girls do. One study on biology students used a tripartite attitude model and found that boys' attitudes were significantly more positive than girls' with regards to the general component as well as the cognitive and affective components. However, no significant gender difference with regards to behavioural attitudes was found in this group of biology students (Fonseca et al., 2012b). There are studies indicating that gender-based attitudes towards, for example, biology, are content specific in that boys and girls show differing attitudes towards specific scientific topics rather than towards general science topics (Potvin \& Hasni, 2014b).

The correlation between students' academic merits, such as grade point averages or standardised test scores, and students' attitudes towards science and/or science topics has been inconclusive or shown no significant correlation in previous studies (Morrell \& Lederman, 1998; Willson, 1983). In Potvin and Hasni (2014) there are indications, though, that there probably is a positive correlation between general educational performance and attitudes towards science. On the other hand, in an analysis of data from the Trends in International Mathematics and Science Study (TIMSS), it was concluded that the "higher the average student achievement, the less positive their attitudes towards science" (Osborne \& Dillon, 2008). The reversed pattern may be explained by that attitudes operate differently on individual and system levels. The negative correlation at country level may be explained along the lines of the so called attitude-achievement paradox which underlines that top-performing countries score low on various attitude scales. That certain cultures differ in modesty have been suggested as an explanation for the phenomenon (Min, Cortina, \& Miller, 2016).

Related research shows that students with parents with a higher level of education show non-significant correlation to positive attitudes or even slightly negative attitudes towards science (George, 2006; Papanastasiou \& Papanastasiou, 2004; Telli, Brok, \& Cakiroglu, 2010). No previous studies specifically investigating the correlation 
between students' attitudes towards modern biotechnology and their general academic merits or the educational level of their parents were found.

That there is a positive correlation between general interest in science and attitudes towards science may not be surprising and has also been confirmed (Tuan, Chin, \& Shieh, 2005). One study pursued this relationship one step further and found a positive correlation between general interest and intrinsic attitudes, while no correlation was found with regards to extrinsic attitudes (Song, 2009). Nevertheless, the correlation between general interest in science and attitudes towards science seems to be undisputed and assumed in science education research.

\section{The Present Study}

Although studies on attitudes towards modern biotechnology have mainly operationalised attitude as a single component, there is reason to believe that the tripartite model would be particularly relevant here as argued earlier. This is because biotechnology education involve elements of ethics and morals, which are not as common in, for example, chemistry, physics, or other content areas of biology. It is thus more likely that students have stronger opinions and attitudes about modern biotechnology than about science in general. Therefore it could be hypothesised that the tripartite model would be more fitting in this context. While it is possible that specific components (affect, behaviour, cognition) can be found in the attitude construct of biotechnology, it is also possible that there is a general component towards biotechnology that goes beyond the specific components. Against this background, the overall aim of this study is to empirically investigate upper secondary students' attitudes towards modern biotechnology using three different theoretical models. As the participants in the present study have different school background (private vs public), come from different educational programs and differ according to their grade and gender, it is possible to test the stability of the different attitude models. The following research questions are focused on in particular:

(1) How are students' attitudes towards biotechnology characterised in terms of factor structure?

(2) How invariant are the different attitude models given students' grade (grades 10-12, ages 15-18), educational programme, school type, gender, and parental education?

\section{DATA AND METHODS}

The main purpose of this study is to explore the attitudes towards modern biotechnology among upper secondary school biology students using a SEM approach. For this purpose, data was obtained from a larger project measuring students' and teachers' interest and attitudes towards biotechnology. Data was collected in the biology classroom environment in Swedish upper secondary schools. In the following section, the participants and variables used in the current study will be described.

\section{Participants}

All Swedish upper secondary schools or educational units $(n=439)$ with national educational programmes with mandatory teaching of the national curriculum course Introduction to Biology (Biologi 1) were invited to participate in an online survey about their interest, attitudes, learning environment with regards to students and biotechnology. The list of schools was obtained from the Swedish National Agency for Education (Skolverket), the responsible school principal (or equivalent) at each school/unit was contacted by e-mail during October 2017, and they each decided on their school's participation. To improve response rates, reminders were sent out in late November and early December 2017. Due to confidentiality, it was not possible to specifically contact nonrespondents, nor was it possible to know which schools actually participated. The online survey questionnaire was administered to the students by teachers in participating schools during the regular class period, and the questionnaires were then answered immediately using students' individual digital devices. The response rate in the classroom was nearly $100 \%$. The teachers instructed the students using questionnaire instructions provided by the researchers. All questionnaires were completed in the period of October to mid-December 2017.

Students in the two upper secondary school programmes Natural Science Programme (Naturvetenskapsprogrammet, NA) and Natural Resource Use Programme (Naturbruksprogrammet, NB) were targeted, as modern biotechnology is included in the programmes' biology courses. The Natural Science Programme is a three-year preuniversity programme for higher education in the sciences, while the Natural Resource Use Programme is a threeyear vocational education programme for students headed for professions within agriculture, forestry, and similar fields. In Sweden, students enter an elected secondary school programme, such as the two mentioned, during the year they turn 16 (grade 10). Students completing the survey were then between 15 and 18 years old and distributed as 626 students in grade 10, 551 in grade 11, 322 in grade 11, and 4 students in other grades. Both public and private schools in Sweden are mandated to adhere to the same national curriculum, have the same funding policy and run under the same national school law. The main difference is that public schools are run by local governments, while 
Table 1. Demographics from survey and national census data for the Natural Science Programme and Natural Resource Use Programme for the 2017-2018 academic school year

\begin{tabular}{|c|c|c|c|c|c|c|}
\hline & & \multicolumn{2}{|c|}{ Survey data } & \multicolumn{2}{|c|}{ National census data } & \multirow{2}{*}{$\begin{array}{c}\text { Difference } \\
\% \\
\end{array}$} \\
\hline & & $\mathbf{n}$ & $\%$ & $\mathbf{n}$ & $\%$ & \\
\hline \multirow{4}{*}{ Parent Education } & High School or less & 311 & 20.7 & 15268 & 29.7 & 9.0 \\
\hline & University & 1088 & 72.4 & 34132 & 66.4 & 6.0 \\
\hline & Other/Don't know & 104 & 6.9 & 2042 & 4.0 & 2.9 \\
\hline & Total & 1503 & & 51442 & & \\
\hline \multirow{4}{*}{ Gender } & Female & 830 & 55.2 & 29067 & 56.5 & 1.3 \\
\hline & Male & 637 & 42.4 & 22375 & 43.5 & 1.1 \\
\hline & Other & 36 & 2.4 & - & - & - \\
\hline & Total & 1503 & & 51442 & & \\
\hline \multirow{4}{*}{$\begin{array}{l}\text { Educational } \\
\text { Programme }\end{array}$} & Natural Science Programme & 1233 & 82.0 & 43028 & 83.6 & 1.6 \\
\hline & $\begin{array}{c}\text { Natural Resource Use } \\
\text { Programme }\end{array}$ & 209 & 13.9 & 8414 & 16.4 & 2.5 \\
\hline & Other/Don't know & 61 & 4.1 & - & - & - \\
\hline & Total & 1503 & & 51442 & & \\
\hline \multirow{4}{*}{$\begin{array}{c}\text { Private/Public } \\
\text { school }\end{array}$} & Private & 336 & 22.4 & 15150 & 29.5 & 7.1 \\
\hline & Public & 1125 & 74.9 & 36292 & 70.5 & 4.3 \\
\hline & Other/Don't know & 42 & 2.8 & - & - & - \\
\hline & Total & 1503 & & 51442 & & \\
\hline \multirow[b]{2}{*}{$\begin{array}{l}\text { Academic merit } \\
\text { score after year } 9\end{array}$} & Natural Science Programme & \multicolumn{2}{|c|}{$300^{*}$} & \multicolumn{2}{|c|}{289} & 3.7 \\
\hline & $\begin{array}{c}\text { Natural Resource Use } \\
\text { Programme }\end{array}$ & \multicolumn{2}{|c|}{$220^{*}$} & \multicolumn{2}{|c|}{210} & 4.5 \\
\hline
\end{tabular}

${ }^{*}=$ approx. (maximum score $=340$ )

private schools typically are run by private educational companies or foundations. Table 1 details some information about the participants from whom the data was collected.

The representativeness of the sample in the survey was controlled for by comparing official demographic national census data from the Swedish National Agency for Education for the 2017-2018 academic school year with survey data (Table 1). The census data was collected by the Swedish National Agency for Education at the end of October 2017, which was in the same time frame as the administration of the survey.

As can be noted, the sample collected in the present study does not differ substantially in representativeness as compared with the national census. It was observed that parents' educational level was somewhat higher in the sample. One reason for this might be that relatively few immigrants, whom generally have lower parental educational levels, are represented at the two educational programs investigated. Information on immigration status was not available in the data and thus this hypothesis cannot be confirmed.

\section{Design of Instrument}

Furthermore, the student questionnaire was constructed to characterise and evaluate upper secondary school students' knowledge, attitudes, and interest in modern biotechnology. The questionnaire was based on a variety of existing validated surveys such as the BELBETS questionnaire (Kidman, 2009), the BAQ questionnaire (Prokop et al., 2007), and the BTS/BLS questionnaire (Haidar et al., 2014). The questions and statements were translated and adapted and attitude questions were aligned with the tripartite model.

The cognitive component consisted of ten items intended to capture the students' perceptions and beliefs about modern biotechnology. Students had three options to answer these statements. True (1), False (-1) and Don't know (0). Five of the items were not too emotive and concerned factual knowledge rather than attitude. By means of an explorative factor analysis the ten items were shown to be multidimensional. For the purposes of the current study five items were deemed adequate. The affective and behavioural components consisted of five Likert-type items each and were measured by five ordinal categories ranging from Strongly disagree to Strongly agree. Table 2 describes the variables used in the study. The Cronbach's alpha for the affective and behavioural scales were acceptable, 0.77 and 0.74 respectively. Alpha for the cognitive scale was 0.53 indicating that another approach should be taken than to use summed scales. An approach with latent variables were therefore suggested. 
Table 2. Description of variables

\begin{tabular}{|c|c|c|c|c|c|c|c|}
\hline $\begin{array}{l}\text { Variable } \\
\text { type }\end{array}$ & $\begin{array}{c}\text { Variable } \\
\text { name }\end{array}$ & Statement & $\mathbf{n}$ & Min & Max & M & SD \\
\hline \multicolumn{8}{|c|}{ Latent Cognition } \\
\hline Manifest & Cog1 & $\begin{array}{l}\text { Eating genetically modified organisms such as genetically modified wheat } \\
\text { or corn has shown to increase the risk of cancer }\end{array}$ & 1503 & -1 & 1 & 0.19 & 0.71 \\
\hline Manifest & $\operatorname{Cog} 2$ & $\begin{array}{l}\text { It is safe for humans to eat the genetically modified organisms that are } \\
\text { available at supermarkets }\end{array}$ & 1503 & -1 & 1 & 0.17 & 0.83 \\
\hline Manifest & $\operatorname{Cog} 3$ & $\begin{array}{l}\text { Genetically modified animals have a poorer quality of life than traditionally } \\
\text { bred animals }\end{array}$ & 1503 & -1 & 1 & -0.06 & 0.81 \\
\hline Manifest & $\operatorname{Cog} 4$ & $\begin{array}{l}\text { Genetically modified plants used for food have been shown to cause } \\
\text { allergies to a greater extent than other bred plants }\end{array}$ & 1503 & -1 & 1 & 0.01 & 0.69 \\
\hline Manifest & $\operatorname{Cog} 5$ & $\begin{array}{l}\text { Farming with genetically modified plants requires more pesticides than } \\
\text { ordinary farming }\end{array}$ & 1503 & -1 & 1 & 0.38 & 0.76 \\
\hline Latent & Affect & & & & & & \\
\hline Manifest & Aff1 & $\begin{array}{l}\text { I think it should be allowed to genetically modify fruit so that it can produce } \\
\text { vaccines }\end{array}$ & 1503 & 1 & 5 & 3.78 & 1.218 \\
\hline Manifest & Aff2 & $\begin{array}{l}\text { I think it should be allowed to genetically modify animals so that they can } \\
\text { produce medicines for humans }\end{array}$ & 1503 & 1 & 5 & 2.74 & 1.353 \\
\hline Manifest & Aff3 & $\begin{array}{l}\text { I think it should be allowed to genetically modify tomatoes so they ripen } \\
\text { more slowly and have a longer shelf life }\end{array}$ & 1503 & 1 & 5 & 3.41 & 1.290 \\
\hline Manifest & Aff4 & I think it should be allowed to genetically modify algae to produce biofuel & 1503 & 1 & 5 & 3.78 & 1.195 \\
\hline Manifest & Aff5 & $\begin{array}{l}\text { I think it should be allowed to genetically modify farmed salmon to make it } \\
\text { grow faster }\end{array}$ & 1503 & 1 & 5 & 2.53 & 1.305 \\
\hline \multicolumn{8}{|c|}{ Latent Behaviour } \\
\hline Manifest & Beh1 & $\begin{array}{l}\text { I would consider eating genetically modified foods if they are cheaper than } \\
\text { regular foods }\end{array}$ & 1503 & 1 & 5 & 2.85 & 1.304 \\
\hline Manifest & Beh2 & $\begin{array}{l}\text { I would consider supporting genetic modification of organisms if they are } \\
\text { good for the environment }\end{array}$ & 1503 & 1 & 5 & 3.87 & 1.110 \\
\hline Manifest & Beh3 & $\begin{array}{l}\text { I would consider taking medicines produced by genetically modified } \\
\text { microorganisms }\end{array}$ & 1503 & 1 & 5 & 3.68 & 1.169 \\
\hline Manifest & Beh4 & $\begin{array}{l}\text { I would consider participating in protests against the use of genetically } \\
\text { modified animals }\end{array}$ & 1503 & 1 & 5 & 2.76 & 1.340 \\
\hline Manifest & Beh5 & $\begin{array}{l}\text { I would consider supporting genetic modification of cereals for the } \\
\text { production of more nutritious foods }\end{array}$ & 1503 & 1 & 5 & 3.53 & 1.186 \\
\hline
\end{tabular}

Note: One item (Beh4) of the Behaviour construct was recoded in the further analyses, as the 'strongly agree' (5) alternative would imply a negative attitude here, as opposed to the other items

\section{Analytical Methods}

The main method of analysis is confirmatory factor analysis (CFA) and SEM with latent variables. The primary purpose of CFA is to determine the number and nature of latent variables or factors (Brown, 2015). CFA was carried out in the first step where measurement models of the attitude constructs were identified. In the second step, the latent variables were related to covariates such as gender in a structural model.

Compared to single indicator approaches, analyses that use latent variables have advantages in large samples, both theoretically and technically (Kline, 2016). Constructs within social science are often difficult to frame with a single indicator since they are not directly observable. However, with latent variables theoretical constructs can be represented in a more comprehensive manner. Moreover, latent variables are in a technical sense free from measurement errors because the variance of different indicators not explained by the latent factor is sorted out. Thus, a latent variable comprises one "true" part, taking the common variance of the indicators into account, and one unexplained part, which is due to measurement error or score unreliability. This allows, from a validity point of view, for an analysis of better quality than would be the case with, for example, multiple regression analysis (MRA). In MRA it is assumed that all predictors are measured without error, which rarely is the case. The analyses were conducted using the computer programmes SPSS version 25 and Mplus version 8 (Muthén \& Muthén, 19982018).

\section{Model Evaluation}

For several decades there has been a discussion around how to best assess model fit in SEM. One reason for the long-lasting debate is that there are no golden rules or explicit cut-off values that indicate whether a model should 
be rejected or accepted (Bentler, 2007; Fan \& Sivo, 2007; Goffin, 2007; Markland, 2007). A reason for the lack of strict cut-off rules is that these values depend on factors such as the types of factor structures, samples sizes, and the size of factor loadings. In the current study, the $\chi^{2}$ goodness-of-fit test was used. Considering that the $\chi^{2}$ is sensitive to sample size, it was combined with three other fit indices. Root mean square error of approximation (RMSEA) takes both the number of observations and free parameters into account. A RMSEA value of 0.05 indicates a close fit, while a value of 0.08 has been suggested as acceptable (Loehlin, 2004). The comparative fit index (CFI) is a fit index that depends on the average size of the correlations in the data. CFI should be as close to 1.0 as possible, and 0.95 is considered an acceptable value. Additionally, the standardized root mean square residual (SRMR) was used, which is the square root of the difference between the residuals of the sample covariance matrix and the hypothesised model. An SRMR value of 0.08 or less has been suggested as necessary for the model to be accepted (Brown, 2015; Hu \& Bentler, 1999).

\section{RESULTS}

To investigate the dimensions of students' attitudes towards modern biotechnology, measurement models of affective, behavioural, and cognitive attitude towards biotechnology were formulated. The affective model obtained poor fit with five indicators and was therefore re-specified. Indicators Aff3 and Aff5 had high degree of commonalitity, which too was indicated by the modification indices. Instead of allowing a covariance between their residuals, only one of them (Aff3) was selected for inclusion in the measurement model. The models are presented in Table 3 along with their factor loadings and model fit.

Table 3. Factor loadings and model fit for tripartite measurement models

\begin{tabular}{cccc}
\hline & Affect & Behaviour & Cognition \\
\hline item1 & $0.736(0.020)$ & $0.708(0.017)$ & $0.635(0.032)$ \\
\hline item2 & $0.506(0.024)$ & $0.625(0.019)$ & $0.483(0.030)$ \\
\hline item3 & $0.664(0.021)$ & $0.733(0.016)$ & $0.335(0.032)$ \\
\hline item4 & $0.646(0.021)$ & $0.770(0.016)$ & $0.481(0.031)$ \\
\hline item5 & & $0.263(0.027)$ & $0.267(0.032)$ \\
\hline Fit index & & 9.453 \\
\hline$\chi 2$ & 0.565 & 21.259 & 5 \\
\hline df & 2 & 5 & 0.0923 \\
\hline$p$ & 0.7540 & 0.0007 & 0.024 \\
\hline \multirow{2}{*}{ RMSEA } & 0.000 & 0.047 & $\mathrm{Cl} 0.000-0.048$ \\
\hline CFI & $0.000-0.035$ & $0.027-0.068$ & 0.991 \\
\hline SRMR & 1.000 & 0.991 & 0.014 \\
\hline
\end{tabular}

Note: Standard errors shown within parentheses

As can be observed, all three models obtained excellent fit to the data. The factor loadings are in most cases high and even. For the behaviour and cognitive factors, one loading is quite modest (item5). Therefore, in order to achieve a more parsimonious model, the items Beh5 and $\operatorname{Cog} 5$ were excluded in the further modeling.

In the next step, a model where all attitude items loaded on the same factor was hypothesised; however, this one-factor (unitary) model obtained poor model fit. Instead, a three-factor (tripartite) model was proposed allowing the three factors to correlate, and with each factor containing only the cognitive, affective, and behavioural items respectively. The one- and three-factor models are presented in Figures 4 and 5. 


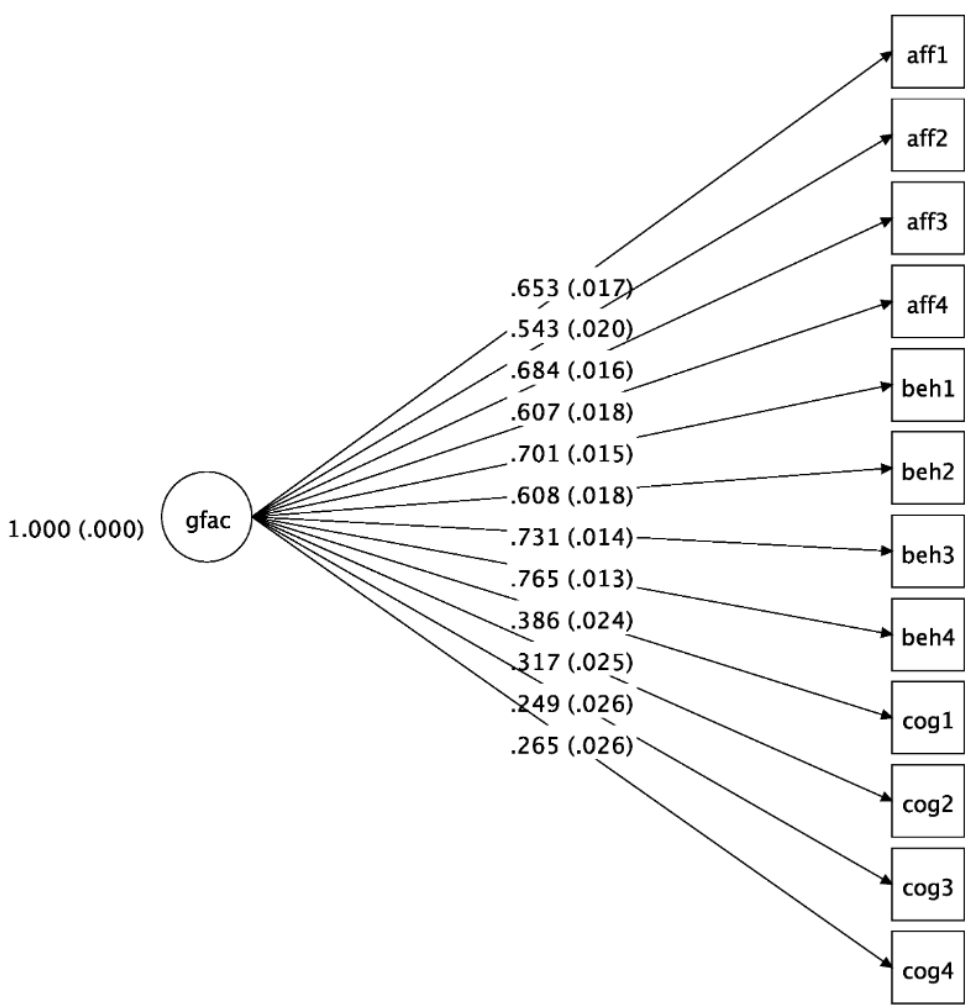

Figure 4. Model fit of the one-factor (unitary) attitude model: $\chi 2=479.162, D f=54, R M S E A=0.072, C l 0.066-0.078, C F I=0.916$, $\mathrm{SRMR}=0.048$

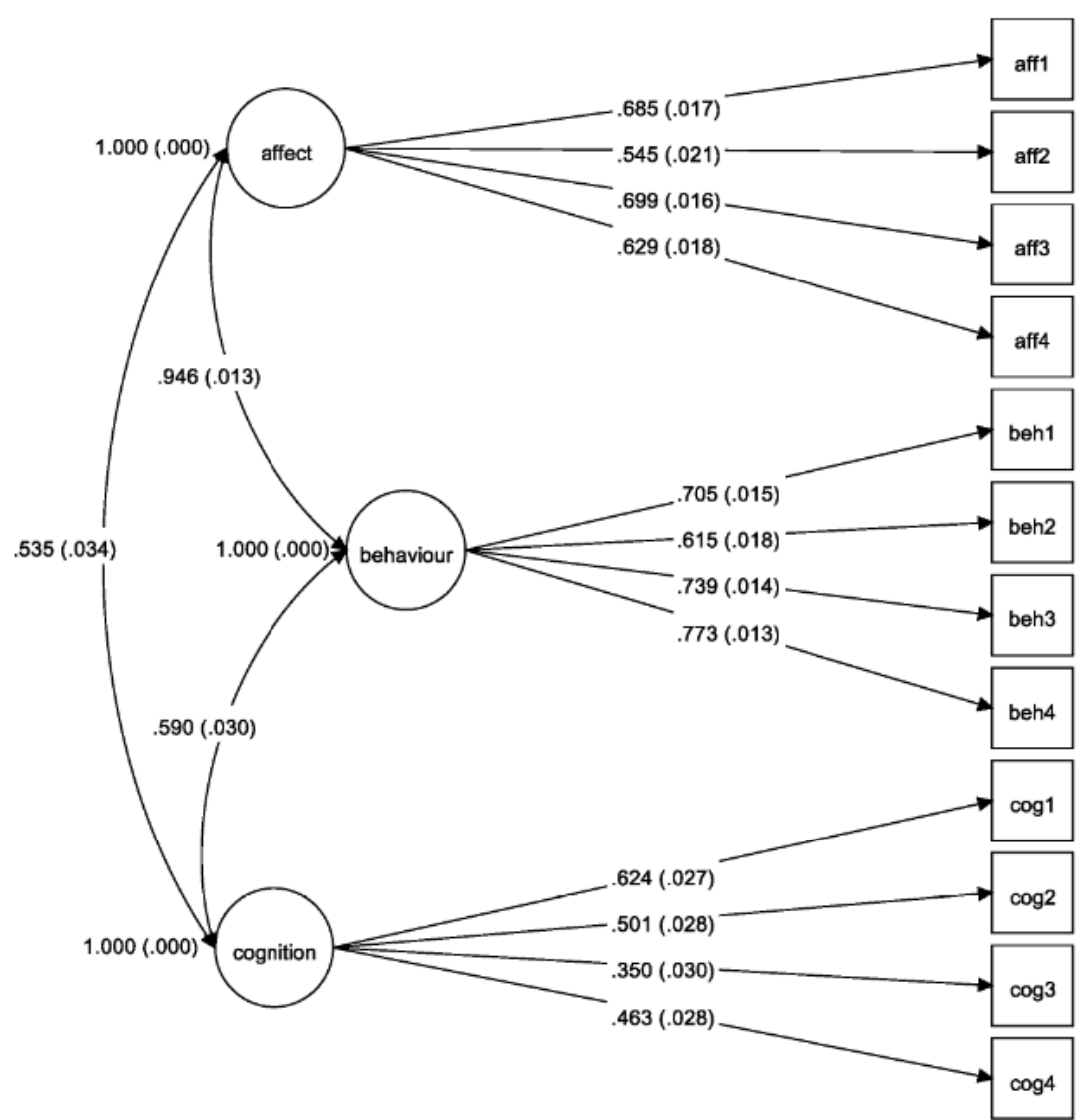

Figure 5. Model fit of the three-factor (tripartite) attitude model: $\chi 2=238.061, D f=51, R M S E A=0.049 \mathrm{Cl} 0.043-0.056, C F I=0.963$, SRMR $=0.028$ 
As is indicated by the fit indices, the one-factor model shows a rather mediocre fit, at least in terms of CFI. While the three-factor model clearly has a better overall fit to the data, the three-factor model shows a substantial overlap between the attitude factors. The correlation between the affective and behavioural factor is about .95, implying that it is difficult to distinguish these constructs on an empirical basis. As for the cognitive factor, it has a lower, yet moderate, correlation to both constructs. This may be explained by the different characteristic of the scale as well as that cognitive dimensions often have rather modest positive or inconclusive correlation with attitudes. These explanations will be further discussed in the next section. In spite of a lower correlation between the cognitive factor and the other two factors, the study show fairly high correlations.

However, since the three components differ in their relations, with the affective and behavioural factors being highly correlated yet another model could be suggested, which represents the attitude construct well. Therefore, the model was reformulated to contain one general factor comprising all items and one bifactor; the cognitive attitude. The general factor in a bifactor model represents the single source of common variance among all items regarding attitudes and is interpreted as the students' general attitudes towards biotechnology, which was labelled general G_attitude. The bifactor, cognition, is unrelated to the general factor, and may represent method artifacts related to the item or facets of content knowledge that could be inherent in the scale. The model is presented in Figure 6.

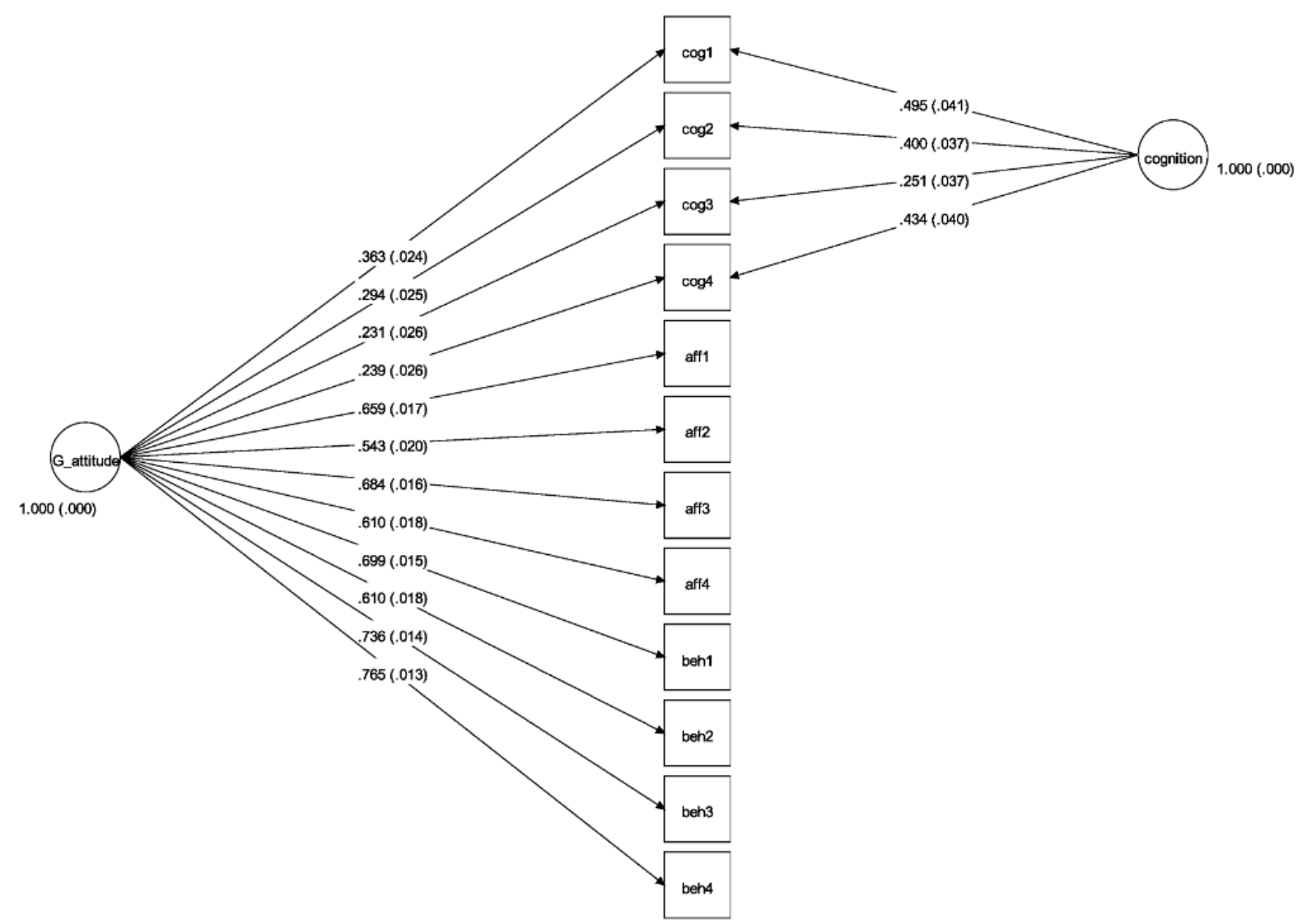

Figure 6. Bifactor model of students' attitudes towards biotechnology. Factor loadings and their standard deviation are presented. Model fit: $\chi 2=254.289, \mathrm{Df}=50, \mathrm{RMSEA}=0.052 \mathrm{Cl} 0.046-0.059, \mathrm{CFI}=0.96, \mathrm{SRMR}=0.028$

The bifactor model showed close fit to the data, to the same magnitude as in the tripartite model. The bifactor model has the advantage in that it takes a more overarching approach to multifaceted constructs than does the tripartite model, for example. A bifactor model includes the general construct, such as a unitary model of attitudes, and a specific construct in the same model. Interestingly, the model with a general factor and a specific cognitive factor of students' attitudes towards biotechnology well represents both theory and data. In order to explore the stability of this model for different student groups measurement invariance testing was carried out for the variables presented in Table 1. 


\section{Are Attitudes Invariant across Student Groups?}

The evaluation of equivalence across groups refers to testing of measurement invariance. Since the sample comprised students from public and private school, students from different educational programs as well as students from different grades (10-12) invariance testing was justified. Taken into account that attitudes often varies for gender measurement invariance for this variable was also examined. The essential question under investigation in the following is thus if the construct attitude towards biotechnology, which was measured using a bifactor model, is more or less the same for different student groups. There are several different types of measurement invariance and authors do not use a common labelling for these types. One common division is configural variance, metric (weak) invariance, scalar (strong) invariance and strict invariance (for a detailed discussion, see, for example, Kline, 2016; Wu, Li, \& Zumbo, 2007). Configural variance assumes that the models are estimated equally across groups and that no restrictions are set for any parameter. The condition for configural variance is that the model fits the data; the factor should thus not be unidimensional for some groups and multi-dimensional for others. Weak invariance (metric invariance) requires equality of unstandardized pattern coefficients. The factor should have the same meaning in all groups. Strong invariance (scalar invariance) requires, besides equal factor loadings, equal unstandardized intercepts over groups. This implies that individuals from the different groups used the response scale in the same way, that is means and standard deviations. Lastly, strict variance, which is the highest level of measurement invariance, assumes equality in error variances and covariances across groups. Thus, the indicators must measure the same factors in each group with same degrees of precision.

The analyses were performed in Mplus, which has a built-in test of configural, metric and scalar invariance. $\chi^{2}$ difference tests are performed for one specific group (i.e., gender) at the time to compare the different levels of invariance but other model fit indices for configural, metric and scalar models will also be compared.

For school-type, the testing indicates strongest invariance, in fact a model with scalar invariance had somewhat better RMSEA and was preferred even though the difference of metric and scalar models were small (Table 4). It was also anticipated that differences in attitude between school-type would be negligible. For parental education, the pattern was the same. One reason for this might have been that the variable used did not differentiate well enough among different levels of parental education. Yet, the attitude construct did not differ for the about $20 \%$ students who had parents with upper secondary schooling or lower only. For the other variables the $\chi^{2}$ difference test was significant, suggesting that the configural model was preferred. In these models, however, it was noted that the model assuming metric invariance were about as good in terms of model fit (CFI, RMSEA, SRMR) as the other configural model. It can be concluded that the bifactor model fits the data for the different groups tested, i.e., it does not fit worse for boys than for girls, and that the factors have the same or similar meaning in the tested groups.

Table 4. Measurement invariance

\begin{tabular}{|c|c|c|c|c|c|c|c|c|c|c|c|c|c|c|c|}
\hline \multirow[t]{2}{*}{ Models Compared } & \multicolumn{3}{|c|}{ Grade } & \multicolumn{3}{|c|}{$\begin{array}{l}\text { Educational } \\
\text { programme }\end{array}$} & \multicolumn{3}{|c|}{ School type } & \multicolumn{3}{|c|}{ Gender } & \multicolumn{3}{|c|}{$\begin{array}{l}\text { Parental } \\
\text { education }\end{array}$} \\
\hline & $x^{2}$ & $\mathrm{df}$ & $\mathrm{p}$ & $x^{2}$ & $\mathrm{df}$ & $p$ & $x^{2}$ & $\mathrm{df}$ & $\mathrm{p}$ & $x^{2}$ & $\mathrm{df}$ & $p$ & $x^{2}$ & $\mathrm{df}$ & $\mathrm{p}$ \\
\hline Metric against Configural & 52.94 & 28 & 0.003 & 29.76 & 14 & 0.01 & 14.47 & 14 & 0.42 & 37.09 & 14 & 0.00 & 16.97 & 14 & 0.26 \\
\hline Scalar against Configural & 109.82 & 48 & 0.00 & 82.49 & 24 & 0.00 & 38.30 & 24 & 0.03 & 161.83 & 24 & 0.00 & 43.16 & 24 & 0.01 \\
\hline Scalar against Metric & 56.88 & 20 & 0.00 & 52.74 & 10 & 0.00 & 23.83 & 10 & 0.01 & 124.74 & 10 & 0.00 & 26.18 & 10 & 0.00 \\
\hline
\end{tabular}

\section{DISCUSSION}

In this study it has shown that there seems to be more to the picture than a unitary model or a tripartite model of attitudes can explain. Data on students' attitudes towards biotechnology showed a better fit to the tripartite model than to the unitary model, but the highly correlated affective and behavioural factors indicated that there should be a general factor that cut across specific factors. Using a bifactor model to disentangle the attitude construct could give a developed understanding of the attitude construct itself.

In attempts to disseminate and explain multifaceted socio-psychological constructs such as attitude, other similar constructs have been investigated using bifactor modeling. Examples can be found in recent studies on constructs such as personality (F. F. Chen, Hayes, Carver, Laurenceau, \& Zhang, 2012), anxiety and depression (Reise, 2012), and safety (Jeong \& Lee, 2016), where fruitful and promising models were constructed, tested, and evaluated. In recent years there have also been articles on didactics where bifactor modeling has been used in conceptualising and measuring the psychological constructs active in educational settings (Reise, 2012). This bifactor model can also serve as an addition to the discourse on upper secondary school biology students' attitudes towards modern biotechnology. Furthermore, there may be aspects of biotechnology education that differ from general science 
education since patterns in the students' attitudes differ from those found in the results of previous research on science attitudes.

The association between the specific factors in the tripartite model showed that the affective and behavioural factors are more closely correlated than the cognitive factor is to either of the two. It has also been indicated in previous research that cognitive factors or domains are not as clearly linked to the general construct as affect and behaviour are (Fonseca et al., 2012b; Sorgo \& Ambrozic-Dolinsek, 2009; Usak et al., 2009).

On the other hand, cognition cannot be disregarded, as it was moderately correlated to the other factors in the construct of attitudes towards modern biotechnology. The results further indicated that cognition fitted as a part of the general attitude factor in which affective and behavioural aspects were also included.

It could be argued that the cognitive component investigated with the instrument used in this study may infact represent cognitive knowledge rather than cognitive attitude. The bifactor model proposed could support this hypothesis since the cognitive items load on the general attitude factor, while a part of their shared variance can be explained by a cognitive component. This further support that there seems to be a cognitive component that does not fit in the general attitude construct. The analysis in this study have thus found that what could be considered cognitive attitude actually hold aspects of cognitive knowledge.

In attempting to explore the invariance of students' attitudes towards modern biotechnology, a particular focus was placed on students' grade (10-12), educational programme, school type, gender, and parental education. All in all the attitude factors showed metric invariance for these groups even though public and private schools was strongly invariant. Despite not finding strong invariance the model fit showed that the bifactor model were suitable for all groups but that the response patterns varied somewhat. This was also anticipated since the older students were more generally more experienced in the subject biotechnology, the educational programmes differed with respect to student background as well as the fact that boys had a more positive attitude than girls. The latter pattern conforms with gender differences found in previous research on attitudes (Crne-Hladnik et al., 2009; Finke \& Kim, 2004; Prokop et al., 2007).

\section{Limitations and Further Research}

By comparing the survey demographic data with national census data from the Swedish National Agency for Education, the survey sample well represented and matched that of the student population on a national level (Table 1). Nevertheless, of the 439 schools initially contacted, relatively few answered the invitation to participate. It may be that schools supplying data were especially positive towards the subject of biotechnology and that the students have more positive attitudes than the average student. Furthermore, it would have been very interesting to connect the teachers' attitudes with students' attitudes, however, due to confidentiality, it was not possible to identify which teachers were associated with their respective students. Another limitation relates to the operationalization of the cognitive scale. Although the cognitive model had excellent fit to the data the item responses were quite heterogenous. Students might have used the scale somewhat differently in that some selected don't know when they were unsure whereas others selected true or false based on guessing. The nature of the scale as well as the result from the bifactor analysis suggests that the cognitive scale could be modelled differently, for example based on latent class analysis or by means of item response theory (IRT). To complement this study with future research, utilisation of other methods and analytical tools would be beneficial to deepen the understanding, on a causal level, of students' attitudes in educational settings towards modern biotechnology.

\section{Conclusions and Implications}

Potential implications for future educational research and educational practices in biotechnology and related areas can be hypothesised beyond what is discussed above. First, different statistical models to evaluate the structure of students' attitudes towards modern biotechnology have been suggested, tested, and evaluated. These models take the discourse on students' attitudes towards modern biotechnology one step further than with previously used attitude models. The findings from this study may play an important role in characterising students' attitudes, and also play a role in developing and evaluating educational practices for the future with these attitudes in mind. Since it has been concluded that all three specific factors do come into play in the general construct, it is suggested that practitioners emphasise all three in the educational setting in order to affect students and consequently develop their interest as well as cognitive skills. The importance of including affective dimensions in science education has been argued and researched in recent years (Alsop, 2016; Rahayu, 2015; Zembylas, 2016). Attitude towards biotechnology may be especially pertinent to work with for practitioners because the many inherently affective and behavioural topics in modern biotechnology do separate the area from other areas of science. In biotechnology education, ethical, emotional, political, and social aspects are often integrated parts; in this way it differs from most other topics or subjects in the natural sciences. For example, there is widespread agreement among scientists that genetically modified food is safe to consume. Yet many people harbour concerns 
about these foods or even oppose their use. As was shown in a study by Fernbach et al. (2019), the more negative attitudes people had towards genetically modified foods, the less objective knowledge about science and genetics they had (Fernbach, Light, Scott, Inbar, \& Rozin, 2019). Additionally, their study showed that those who are the most extreme opponents to genetically modified food perceive their knowledge to be the highest. In the light of these results, it appears to be of vast importance for teachers to work with attitudes towards biotechnology to avoid misunderstandings; this work may also be very beneficial for students' science knowledge in the long run. Future research on teaching in biotechnology is urged to shed more light on how students' attitudes can be developed but also how such development can influence cognitive knowledge and student achievement.

\section{ACKNOWLEDGEMENTS}

We would like to thank Henrik Aronsson, Jesper Boesen and Angela Wulff for critical reading of the manuscript and to fellow colleagues at the Centre for Education Science and Teacher Research at the University of Gothenburg for fruitful and constructive feedback.

\section{REFERENCES}

Aikenhead, G. S. (2004). The humanistic and cultural aspects of science \& technology education. Paper presented at the Science and Technology Education for a Diverse World-dilemmas, needs and partnerships. International Organization for Science and Technology Education (IOSTE) XIth Symposium Proceedings, Lublin, Poland.

Ajzen, I. (2001). Nature and operation of attitudes. Annual review of psychology, 52(1), 27-58. https:/ / doi.org/10.1146/annurev.psych.52.1.27

Ajzen, I., \& Fishbein, M. (2000). Attitudes and the attitude-behavior relation: Reasoned and automatic processes. European review of social psychology, 11(1), 1-33. https:/ / doi.org/10.1080/14792779943000116

Alsop, S. (2016). Encountering science education's capacity to affect and be affected. Cultural Studies of Science Education, 11(3), 551-565. https:/ / doi.org/10.1007/s11422-015-9692-6

Bentler, P. M. (2007). On tests and indices for evaluating structural models. Personality and Individual Differences, 42(5), 825-829. https:/ / doi.org/10.1016/j.paid.2006.09.024

Breckler, S. J. (1984). Empirical validation of affect, behavior, and cognition as distinct components of attitude. Journal of personality and social psychology, 47(6), 1191-1205. https:/ / doi.org/10.1037/0022-3514.47.6.1191

Brown, T. A. (2015). Confirmatory Factor Analysis for Applied Research. New York, NY: Guilford Press.

Casanoves, M., Gonzalez, A., Salvado, Z., Haro, J., \& Novo, M. (2015). Knowledge and Attitudes towards Biotechnology of Elementary Education Preservice Teachers: The first Spanish experience. International Journal of Science Education, 37(17), 2923-2941. https:/ / doi.org/10.1080/09500693.2015.1116718

Chen, F. F., Hayes, A., Carver, C. S., Laurenceau, J.-P., \& Zhang, Z. (2012). Modeling General and Specific Variance in Multifaceted Constructs: A Comparison of the Bifactor Model to Other Approaches. Journal of Personality, 80(1), 219-251. https:// doi.org/10.1111/j.1467-6494.2011.00739.x

Chen, S. Y., \& Raffan, J. (1999). Biotechnology: Student's knowledge and attitudes in the UK and Taiwan. Journal of Biological Education, 34(1), 17-23. https:// doi.org/10.1080/00219266.1999.9655678

Chen, S. Y., Chu, Y. R., Lin, C. Y., \& Chiang, T. Y. (2016). Students' knowledge of, and attitudes towards biotechnology revisited, 1995-2014: Changes in agriculture biotechnology but not in medical biotechnology. Biochemistry and Molecular Biology Education, 44(5), 475-491. https:/ / doi.org/10.1002/bmb.20969

Christidou, V. (2011). Interest, Attitudes and Images Related to Science: Combining Students' Voices with the Voices of School Science, Teachers, and Popular Science. International Journal of Environmental and Science Education, 6(2), 141-159.

Costa-Font, J., \& Mossialos, E. (2006). The public as a limit to technology transfer: the influence of knowledge and beliefs in attitudes towards biotechnology in the UK. The Journal of Technology Transfer, 31(6), 629-645. https:/ / doi.org/10.1007/s10961-006-0019-3

Crne-Hladnik, H., Peklaj, C., Kosmelj, K., Hladnik, A., \& Javornik, B. (2009). Assessment of Slovene secondary school students' attitudes to biotechnology in terms of usefulness, moral acceptability and risk perception. Public Understanding of Science, 18(6), 747-758. https: / doi.org/10.1177/ 0963662509336761

Dawson, V. (2006). An Exploration of High School (12-17 Year Old) Students' Understandings of, and Attitudes towards Biotechnology Processes. Research in Science Education, 37(1), 59-73. https:/ / doi.org/10.1007/s11165-006-9016-7

Dawson, V., \& Schibeci, R. (2003). Western Australian high school students' attitudes towards biotechnology processes. Journal of Biological Education, 38(1), 7-12. https:/ / doi.org/10.1080/00219266.2003.9655889 
Eagly, A. H., \& Chaiken, S. (1993). The psychology of attitudes. Orlando, FL, US: Harcourt Brace Jovanovich College Publishers.

Eagly, A. H., \& Chaiken, S. (1998). Attitude structure and function. In D. T. Gilbert, S. T. Fiske, \& G. Lindzey (Eds.), The handbook of social psychology (pp. 269-322). New York: McGraw-Hill.

Fan, X., \& Sivo, S. A. (2007). Sensitivity of Fit Indices to Model Misspecification and Model Types. Multivariate Behavioral Research, 42(3), 509-529. https:/ / doi.org/10.1080/00273170701382864

Fazio, R. H., \& Olson, M. A. (2007). Attitudes: Foundations, functions, and consequences. In M. A. Hogg \& J. Cooper (Eds.), The Sage handbook of social psychology (pp. 123-145). London: SAGE Publications Ltd. https:// doi.org/10.4135/9781848608221.n6

Fernbach, P. M., Light, N., Scott, S. E., Inbar, Y., \& Rozin, P. (2019). Extreme opponents of genetically modified foods know the least but think they know the most. Nature Human Behaviour, 3(3), 251-256. https:/ / doi.org/10.1038/s41562-018-0520-3

Finke, M. S., \& Kim, H. (2004). Attitudes about genetically modified foods among Korean and American college students. AgBioForum, 6(4), 191-197.

Fonseca, M. J., Costa, P., Lencastre, L., \& Tavares, F. (2012a). Disclosing biology teachers' beliefs about biotechnology and biotechnology education. Teaching and Teacher Education, 28(3), 368-381. https:/ / doi.org/10.1016/j.tate.2011.11.007

Fonseca, M. J., Costa, P., Lencastre, L., \& Tavares, F. (2012b). Multidimensional analysis of high-school students' perceptions about biotechnology. Journal of Biological Education, 46(3), 129-139. https:/ / doi.org/10.1080/00219266.2011.634019

France, B. (2007). Location, Location, Location: Positioning Biotechnology Education for the 21st Century. Studies in Science Education, 43(1), 88-122. https:/ / doi.org/10.1080/03057260708560228

Gaskell, G., Allum, N., Wagner, W., Kronberger, N., Torgersen, H., Hampel, J., \& Bardes, J. (2004). GM Foods and the Misperception of Risk Perception. Risk Analysis, 24(1), 185-194. https://doi.org/10.1111/j.02724332.2004.00421.x

George, R. (2006). A cross-domain analysis of change in students' attitudes toward science and attitudes about the utility of science. International Journal of Science Education, 28(6), 571-589. https://doi.org/10.1080/ 09500690500338755

Gilbert, J. K. (2006). On the nature of "context" in chemical education. International Journal of Science Education, 28(9), 957-976. https:/ / doi.org/10.1080/09500690600702470

Goffin, R. D. (2007). Assessing the adequacy of structural equation models: Golden rules and editorial policies. Personality and Individual Differences, 42(5), 831-839. https:/ / doi.org/10.1016/j.paid.2006.09.019

Haidar, H., Chouman, M., \& Tayeh, P. A. (2014). Attitudes of Lebanese Secondary School Students and Teachers towards Biotechnology and its Teaching. American Journal of Educational Research, 2(6), 430-435. https:/ / doi.org/10.12691/education-2-6-15

Hu, L., \& Bentler, P. M. (1999). Cutoff criteria for fit indexes in covariance structure analysis: conventional versus new alternatives. Structural Equation Modeling, 6. https:/ / doi.org/10.1080/10705519909540118

Jeong, H., \& Lee, W. (2016). The Pure and the Overarching: An Application of Bifactor Model to Safety Attitudes Questionnaire. Biometrics \& Biostatistics International Journal, 4(6), 110. https://doi.org/10.15406/bbij.2016. 04.00110

Kidman, G. (2009). Attitudes and interests towards biotechnology: The mismatch between students and teachers. Eurasia Journal of Mathematics, Science and Technology Education, 5(2), 135-143. https://doi.org/10.12973/ ejmste/75265

Kline, R. B. (2016). Principles and practice of structural equation modeling (4th ed.). New York, NY: The Guildford Press.

Klop, T. (2008). Attitudes of secondary school students towards modern biotechnology. (Doctoral Thesis). Erasmus Universiteit, Rotterdam.

Klop, T., Severiens, S. E., Knippels, M. C. P. J., van Mil, M. H. W., \& Ten Dam, G. T. M. (2010). Effects of a Science Education Module on Attitudes towards Modern Biotechnology of Secondary School Students. International Journal of Science Education, 32(9), 1127-1150. https:/ / doi.org/10.1080/09500690902943665

Koballa Jr, T. R. (1988). Attitude and related concepts in science education. Science education, 72(2), 115-126. https:// doi.org/10.1002/sce.3730720202

Koballa Jr, T. R., \& Glynn, S. M. (2007). Attitudinal and motivational constructs in science learning. In S. K. Abell \& N. G. Lederman (Eds.), Handbook of research on science education (pp. 75-102). Mahwah, NJ: Routledge. 
Loehlin, J. C. (2004). Latent variable models: An introduction to factor, path, and structural equation analysis (4th ed.). Mahwah, N.J.: L. Erlbaum Associates. https:/ / doi.org/10.4324/9781410609823

Magnusson, M. K., \& Hursti, U.-K. K. (2002). Consumer attitudes towards genetically modified foods. Appetite, 39(1), 9-24. https:/ / doi.org/10.1006/appe.2002.0486

Markland, D. (2007). The golden rule is that there are no golden rules: A commentary on Paul Barrett's recommendations for reporting model fit in structural equation modelling. Personality and Individual Differences, 42(5), 851-858. https:/ / doi.org/10.1016/j.paid.2006.09.023

Min, I., Cortina, K. S., \& Miller, K. F. (2016). Modesty bias and the attitude-achievement paradox across nations: A reanalysis of TIMSS. Learning and Individual Differences, 51, 359-366. https:// doi.org/10.1016/j.lindif.2016. 09.008

Morrell, P. D., \& Lederman, N. G. (1998). Student's Attitudes Toward School and Classroom Science: Are They Independent Phenomena? School Science and Mathematics, 98(2), 76-83. https://doi.org/10.1111/j.19498594.1998.tb17396.x

Mowen, D. L., Roberts, T. G., Wingenbach, G. J., \& Harlin, J. F. (2007). Biotechnology: An Assessment of Agricultural Science Teachers' Knowledge and Attitudes. Journal of Agricultural Education, 48(1), 42-51. https:/ / doi.org/10.5032/jae.2007.01042

Muthén, L. K., \& Muthén, B. O. (1998-2018). Mplus User's Guide. Los Angeles, CA: Muthén \& Muthén.

Nordqvist, O., \& Aronsson, H. (2019). It is time for a new direction in biotechnology education research. Biochemistry and Molecular Biology Education, 47(2), 189-200. https:/ / doi.org/10.1002/bmb.21214

Osborne, J., \& Dillon, J. (2008). Science education in Europe: Critical reflections (Vol. 13): London: The Nuffield Foundation.

Osborne, J., Simon, S., \& Collins, S. (2003). Attitudes towards science: A review of the literature and its implications. International Journal of Science Education, 25(9), 1049-1079. https:/ / doi.org/10.1080/0950069032000032199

Papanastasiou, C., \& Papanastasiou, E. C. (2004). Major influences on attitudes toward science. Educational research and Evaluation, 10(3), 239-257. https://doi.org/10.1076/edre.10.3.239.30267

Pardo, R., \& Calvo, F. (2002). Attitudes toward science among the European public: a methodological analysis. Public Understanding of Science, 11(2), 155-195. https:/ / doi.org/10.1088/0963-6625/11/2/305

Potvin, P., \& Hasni, A. (2014a). Analysis of the Decline in Interest Towards School Science and Technology from Grades 5 Through 11. Journal of Science Education and Technology, 23(6), 784-802. https:/ / doi.org/10.1007/s10956-014-9512-x

Potvin, P., \& Hasni, A. (2014b). Interest, motivation and attitude towards science and technology at K-12 levels: a systematic review of 12 years of educational research. Studies in Science Education, 50(1), 85-129. https://doi.org/10.1080/03057267.2014.881626

Prokop, P., Lešková, A., Kubiatko, M., \& Diran, C. (2007). Slovakian Students' Knowledge of and Attitudes toward Biotechnology. International Journal of Science Education, 29(7), 895-907. https:/ / doi.org/10.1080/09500690600969830

Rahayu, S. (2015). Evaluating the affective dimension in chemistry education. In M. O. Murat Kahveci (Ed.), Affective dimensions in chemistry education (pp. 29-49): Springer. https://doi.org/10.1007/978-3-662-45085-7_2

Reise, S. P. (2012). The Rediscovery of Bifactor Measurement Models. Multivariate Behavioral Research, 47(5), 667696. https:/ / doi.org/10.1080/00273171.2012.715555

Rosenberg, M. J., \& Hovland, C. I. (1960). Cognitive, affective and behavioural components of attitudes. In M. J. Rosenberg \& C. I. Hovland (Eds.), Attitude organisation and change: An analysis of consistency among attitude components (pp. 1-14). New Have, CT: Yale University Press.

Severcan, F., Ozan, A., \& Haris, P. I. (2000). Development of biotechnology education in Turkey. Biochemistry and Molecular Biology Education, 28(1), 36-38. https:/ / doi.org/10.1016/S0307-4412(99)00116-8

Song, J. (2009). The Effects of Dichotomous Attitudes toward Science on Interest and Conceptual Understanding in Physics AU - Kim, Minkee. International Journal of Science Education, 31(17), 2385-2406. https:/ / doi.org/10.1080/09500690802563316

Sorgo, A., \& Ambrozic-Dolinsek, J. (2009). The relationship among knowledge of, attitudes toward and acceptance of genetically modified organisms (GMOs) among Slovenian teachers. Electronic Journal of Biotechnology, 12(4). https:/ / doi.org/10.2225/vol12-issue4-fulltext-1

Telli, S., Brok, P. d., \& Cakiroglu, J. (2010). The importance of teacher-student interpersonal relationships for Turkish students' attitudes towards science. Research in Science E Technological Education, 28(3), 261-276. https:/ / doi.org/10.1080/02635143.2010.501750 
Tuan, H.-L., Chin, C. C., \& Shieh, S. H. (2005). The development of a questionnaire to measure students' motivation towards science learning. International Journal of Science Education, 27(6), 639-654. https:/ / doi.org/10.1080/0950069042000323737

Usak, M., Erdogan, M., Prokop, P., \& Ozel, M. (2009). High School and University Students' Knowledge and Attitudes Regarding Biotechnology. Biochemistry and Molecular Biology Education, 37(2), 123-130. https:/ / doi.org/10.1002/bmb.20267

Weinburgh, M. H., \& Englehard Jr, G. (1994). Gender, prior academic performance and beliefs as predictors of attitudes toward biology laboratory experiences. School Science and Mathematics, 94(3), 118-123. https://doi.org/10.1111/j.1949-8594.1994.tb15635.x

Willson, V. L. (1983). A meta-analysis of the relationship between science achievement and science attitude: Kindergarten through college. Journal of Research in Science Teaching, 20(9), 839-850. https://doi.org/10.1002/tea.3660200906

Wu, A. D., Li, Z., \& Zumbo, B. D. (2007). Decoding the meaning of factorial invariance and updating the practice of multi-group confirmatory factor analysis: A demonstration with TIMSS data. Practical Assessment, Research and Evaluation, 12(3), 1-26.

Zacharia, Z., \& Barton, A. C. (2004). Urban middle-school students' attitudes toward a defined science. Science education, 88(2), 197-222. https://doi.org/10.1002/sce.10110

Zeller, M. F. (1994). Biotechnology in the high school biology curriculum: the future is here! The American Biology Teacher, 56, 460-464. https:/ / doi.org/10.2307/4449889

Zembylas, M. (2016). Making sense of the complex entanglement between emotion and pedagogy: contributions of the affective turn. Cultural Studies of Science Education, 11(3), 539-550. https://doi.org/10.1007/s11422-014$9623-y$

\section{http://www.ejmste.com}

